\title{
Cloud-resolving modelling of aerosol indirect effects in idealised radiative-convective equilibrium with interactive and fixed sea surface temperature
}

\author{
M. F. Khairoutdinov ${ }^{1}$ and C.-E. Yang ${ }^{1, *}$ \\ ${ }^{1}$ School of Marine and Atmospheric Sciences, Stony Brook University, Stony Brook, New York, USA \\ * current address: Department of Civil and Environmental Engineering, University of Tennessee, Knoxville, TN, USA \\ Correspondence to: M. F. Khairoutdinov (marat.khairoutdinov@ stonybrook.edu)
}

Received: 9 October 2012 - Published in Atmos. Chem. Phys. Discuss.: 13 November 2012

Revised: 13 March 2013 - Accepted: 14 March 2013 - Published: 18 April 2013

\begin{abstract}
The study attempts to evaluate the aerosol indirect effects over tropical oceans in regions of deep convection applying a three-dimensional cloud-resolving model run over a doubly-periodic domain. The Tropics are modelled using a radiative-convective equilibrium idealisation when the radiation, turbulence, cloud microphysics and surface fluxes are explicitly represented while the effects of large-scale circulation are ignored. The aerosol effects are modelled by varying the number concentration of cloud condensation nuclei $(\mathrm{CCN})$ at $1 \%$ supersaturation, which serves as a proxy for the aerosol amount in the environment, over a wide range, from pristine maritime $\left(50 \mathrm{~cm}^{-3}\right)$ to polluted $\left(1000 \mathrm{~cm}^{-3}\right)$ conditions. No direct effects of aerosol on radiation are included. Two sets of simulations have been run: fixed (noninteractive) sea surface temperature (SST) and interactive SST as predicted by a simple slab-ocean model responding to the surface radiative fluxes and surface enthalpy flux. Both sets of experiments agree on the tendency of increased aerosol concentrations to make the shortwave cloud forcing more negative and reduce the longwave cloud forcing in response to increasing CCN concentration. These, in turn, tend to cool the SST in interactive-SST case. It is interesting that the absolute change of the SST and most other bulk quantities depends only on relative change of $\mathrm{CCN}$ concentration; that is, same SST change can be the result of doubling CCN concentration regardless of clean or polluted conditions. It is found that the 10-fold increase of CCN concentration can cool the SST by as much as $1.5 \mathrm{~K}$. This is quite comparable to $2.1-2.3 \mathrm{~K}$ SST warming obtained in a simulation for clean maritime conditions, but doubled $\mathrm{CO}_{2}$ concentra-
\end{abstract}

tion. Assuming the aerosol concentration has increased from preindustrial time by $30 \%$, the radiative forcing due to indirect aerosol effects is estimated to be $-0.3 \mathrm{~W} \mathrm{~m}^{-2}$. It is found that the indirect aerosol effect is dominated by the first (Twomey) effect. Qualitative differences between the interactive and fixed SST cases have been found in sensitivity of the hydrological cycle to the increase in $\mathrm{CCN}$ concentration; namely, the precipitation rate shows some tendency to increase in fixed SST case, but robust tendency to decrease in interactive SST case.

\section{Introduction}

Atmospheric aerosols play an important role in the Earth's radiative budget. The aerosol particles can directly scatter and absorb solar and terrestrial radiation. They can also indirectly influence microphysics and, hence, optical properties of clouds (e.g., Lohmann and Feichter, 2005). By convention, the aerosol indirect effects (AIEs) are subdivided into subcategories depending on their effects on cloud properties. For example, the effect of aerosols on cloud albedo is called the first indirect or Twomey effect (Twomey, 1974), the effect on precipitation efficiency and cloud water path (Albrecht, 1989) and cloud lifetime (Pincus and Baker, 1994) is generally referred to as the second indirect effect. The current consensus reflected in the Fourth Assessment Report of the Intergovernmental Panel on Climate Change (IPCC, 2007) is that aerosols have a predominantly cooling effect on climate with the magnitude of the forcing similar to the net radiative 
forcing due to anthropogenic greenhouse gases. However, the magnitude of aerosol cooling remains highly uncertain, especially for the indirect effects, because of the complicated nature of the interactions between aerosols and clouds.

The bulk of estimates for the AIEs on global climate come from modelling studies that use general circulation models (GCMs) and cloud-resolving models (CRMs). The GCMs generally do not resolve individual clouds; therefore, virtually all the complexities of aerosol-cloud-radiation interactions have to be parameterised (e.g., Abdul-Razzak and Ghan, 2002; Nenes and Seinfeld, 2003; Liu and Penner, 2005; Hoose et al., 2010). On the other hand, many details of these interactions including convection, large-scale forcing, aerosol, cloud microphysics and radiation can be explicitly represented by CRMs (e.g., Lu and Seinfeld, 2005; Grabowski, 2006; Tao et al., 2007; van den Heever et al., 2011; Morrison and Grabowski, 2011). Recently, a GCM that uses a CRM as a super-parameterisation of clouds has been developed to link the explicitly simulated clouds and aerosol processes on global scale (Wang et al., 2011).

In this study, we use the CRM approach to look at the AIEs on deep tropical convection. As the Tropics occupy about half of Earth's surface, the importance of aerosol effects on the Tropics cannot be overemphasised in the context of a changing global climate. We use the radiative-convective equilibrium (RCE) as a proxy for the tropical atmosphere (e.g., Renno et al., 1994). In RCE, the effects of large-scale circulation are ignored, so that the convection balances the destabilisation only by radiation and surface enthalpy fluxes. The RCE has been rather extensively used in the past to study processes driving the hydrological cycle in the Tropics (e.g., Tompkins and Craig, 1998; Xu and Randall, 1999; Grabowski, 2006; Stephens et al., 2008; Romps, 2011). Previous CRM studies of AIEs have examined the variations of tropical convection over the ocean with different sea-surface temperature (SST), which was prescribed from observations or simply fixed at some value (e.g., Grabowski, 2006; van den Heever et al., 2011; Morrison and Grabowski, 2011). The AIEs in the case of the fixed SST can be viewed as the fast response of a cloudy atmosphere to aerosol forcing on relatively short time scales when the SST does not have enough time to respond due to the ocean's large thermal inertia. However, the prolonged changes in aerosol forcing and associated imbalance of the energy budget at the surface will change the SST, which, in turn, will further modulate the hydrological cycle and optical properties of clouds and, hence, should be considered the integral part of the AIEs relevant to the climate-change problem. In this study, we examine the effect of changing aerosol concentration on the SST predicted by a simple slab-ocean model.

The paper is organised as follows. Section 2 describes the CRM model and experimental setup. Section 3 presents the results. Section 4 provides conclusions and summary.

\section{Model description and setup}

\subsection{Model description}

The CRM used in this study is the System for Atmospheric Modeling (SAM; Khairoutdinov and Randall, 2003), version 6.8. The dynamical core solves non-hydrostatic momentum equations in anelastic approximation. The prognostic thermodynamic variable is the liquid/ice static energy, which is conserved in all moist adiabatic processes, such as condensation, evaporation, freezing and melting. The subgrid-scale fluxes are modelled using eddy diffusivity/conductivity coefficients computed by the Smagorinsky-Lilly closure. The radiation scheme is a Rapid Radiative Transfer Model (RRTM; Iacono et al., 2008). The surface sensible and latent heat fluxes are computed based on Monin-Obukhov similarity. The cloud microphysics is modelled using a two-moment bulk microphysical scheme of Morrison et al. (2005), which predicts the mixing ratio and number concentration of each of the water species, namely, cloud water, pristine cloud ice, rain, snow and graupel. In implementation for SAM, the cloud water and water vapour have been combined into a single variable, and the cloud water is diagnosed assuming no supersaturation. The source of cloud droplet number concentration is described assuming that the number of activated cloud condensation nuclei (CCN) depends on the supersaturation according to the power-law $N=C_{\mathrm{CCN}} S^{k}$, where $C_{\mathrm{CCN}}$ is the prescribed concentration of $\mathrm{CCN}$ active at $1 \%$ supersaturation $S$, and $k$ is a constant set in this study to 0.4 , which is a typical value for maritime conditions (Pruppacher and Klett, 1997). The change of the parameter $C_{\mathrm{CCN}}$ serves as a proxy for the change of aerosol burden. The CCN activation at the cloud base is parameterised using the vertical velocity and $\mathrm{CCN}$ spectrum parameters following Twomey (1959). Note, that no direct effect of specified CCN on clearsky radiation is included in this study. Also, no effect of changing ice nuclei concentration has been studied.

The SST $T_{\mathrm{S}}$ can be specified or calculated using a simple slab-ocean model. In this model, the ocean mixed layer with prescribed depth $h$ and heat capacity of water $c_{\mathrm{W}}$ can change its heat content per unit area $c_{\mathrm{w}} h T_{\mathrm{S}}$ through the surface radiation fluxes, enthalpy fluxes and prescribed ocean-transport flux (so called q-flux). The surface fluxes can vary horizontally depending on the atmospheric conditions above; however, the SST is horizontally uniform.

\subsection{Experimental design}

Each experiment in this study uses a three-dimensional doubly periodic domain with $128 \times 128$ grid cells in horizontal with $1 \mathrm{~km}$ grid spacing. The vertical domain has 64 grid levels with the top at $28 \mathrm{~km}$ and variable grid spacing, from $75 \mathrm{~m}$ near the surface to $500 \mathrm{~m}$ in the middle and upper troposphere, and coarser in stratosphere. The time step is $10 \mathrm{~s}$. There is a Newtonian damping layer above $20 \mathrm{~km}$ to 
minimise the effect of gravity wave reflection from the domain top. The radiative heating rates are updated every 45 time steps using time-averaged thermodynamic and cloud fields. The incoming solar radiation is prescribed as perpetual insolation of $255 \mathrm{~W} \mathrm{~m}^{-2}$. The value is chosen to make the average top-of-atmosphere and, hence, the surface flux imbalance be close to zero. There is no large-scale forcing, no Coriolis force and no mean wind. To initialise convection, some random small-amplitude noise is added to the temperature field near the surface.

Two sets of model runs are performed as summarised by Table 1. In the first set, denoted as iSST, with the prefix IA, the SST is interactive as predicted by the slab ocean model. In the second set, denoted as fSST, with the prefix FA, the SST is fixed at $300 \mathrm{~K}$. Each set contains five runs that differ only by the prescribed $C_{\mathrm{CCN}}$ parameter in the range from $50 \mathrm{~cm}^{-3}$ to $1000 \mathrm{~cm}^{-3}$, representing the range of conditions, from pristine maritime to polluted continental-like. All runs use 355 ppmv for $\mathrm{CO}_{2}$ concentration as the "present" value with the exception of IA2CO2, which is identical to IA100, but with $\mathrm{CO}_{2}$ concentration doubled. The runs FA100 and IA100 are the control representing typical clean maritime conditions. The choice for the value for perpetual insolation keeps the equilibrium SST in the IA100 run close to $300 \mathrm{~K}$, so the statistics of the IA100 and FA100 runs are quite similar. The slab-ocean's mixed layer depth is set to relatively deep $10 \mathrm{~m}$ to reduce SST noise. Each simulation was run for 700 days. The initial temperature, water vapour and SST were taken from a small-domain RCE run; however, we do not show the initial profile as no sensitivity to the initial conditions is expected in 700 day long runs. The last 100 days of each run are used for statistics sampling.

The evolution of the SST for each interactive run is shown in Fig. 1, with the final SSTs listed in Table 2. Unfortunately, due to relatively large thermal inertia of the ocean slab, even the runtime as long as the 700 days has not been sufficient for the SSTs to reach the exact equilibrium, especially for the pristine (IA50) and continental-like (IA1000) conditions. We estimated the equilibrium SST for each iSST run by regressing a simple exponential-decay function against the evolving SSTs over the last 400 simulation days. We have found that the SSTs at the end of the least equilibrated IA50 and IA1000 runs may still be within $0.25 \mathrm{~K}$ and $0.1 \mathrm{~K}$, respectively, from the equilibrium. It has also been estimated that it would take another 1000 simulation days to get the SSTs to within $0.05 \mathrm{~K}$ from the estimated equilibrium values, which would add considerably to already large computational expense. We believe, however, that the performed runs are sufficiently close to the corresponding equilibrium SSTs and running them longer would not change the main results and conclusions of this study.
Table 1. List of simulations.

\begin{tabular}{ll|ll}
\hline \multicolumn{2}{c|}{ Interactive SST } & \multicolumn{2}{c}{ Fixed SST } \\
\hline Case & $C_{\mathrm{CCN}}\left(\mathrm{cm}^{-3}\right)$ & Case & $C_{\mathrm{CCN}}\left(\mathrm{cm}^{-3}\right)$ \\
\hline IA50 & 50 & FA50 & 50 \\
IA100 & 100 & FA100 & 100 \\
IA200 & 200 & FA200 & 200 \\
IA500 & 500 & FA500 & 500 \\
IA1000 & 1000 & FA1000 & 1000 \\
IA2CO2 & 100 & & \\
\hline
\end{tabular}

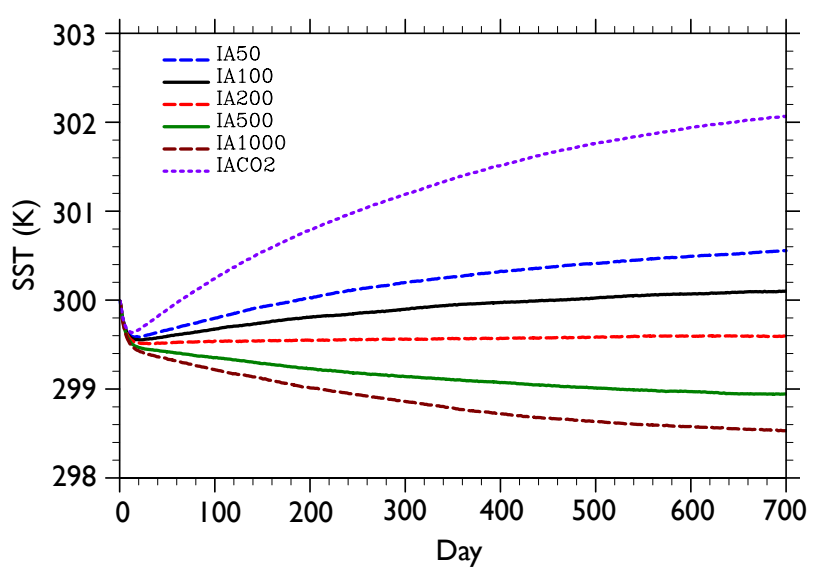

Fig. 1. Time evolution of the SST in interactive-SST runs.

\section{Results}

\subsection{Sensitivity of sea surface temperature to $\mathrm{CCN}$ count}

According to the first aerosol indirect effect, increasing the CCN number concentration increases the cloud droplets' concentration, but reduces their size, which in turn increases the cloud shortwave albedo and, hence, reduces the amount of solar radiation reaching the ocean. As a consequence, the equilibrium SST decreases. This notion is well supported by Fig. 2a, which shows a rather significant decrease of SST by as much as $2 \mathrm{~K}$ when $\mathrm{CCN}$ count increases from values characteristic of pristine maritime to values characteristic of polluted continental-like conditions. It is apparent that the SST change in response to the same absolute change of CCN count is substantially higher for clean conditions than polluted conditions. However, the sensitivity of SST to the relative change of $\mathrm{CCN}$ count appears to be independent of the $\mathrm{CCN}$ count as demonstrated by Fig. 2b, which is similar to Fig. 2a, but uses logarithmic rather than linear scale for the horizontal axis. The constant slope of the SST dependence in Fig. $2 \mathrm{~b}$ indicates that doubling the $\mathrm{CCN}$ count from 500 to $1000 \mathrm{~cm}^{-3}$ has the same effect on SST as doubling from 50 to $100 \mathrm{~cm}^{-3}$. Similar behaviour is found for most other bulk quantities; therefore, as in some other studies of the AIEs (e.g., Platnick and Oreopoulos, 2008), we define a relative 
Table 2. Simulation results (see Table 3 for the list of abbreviations).

\begin{tabular}{lrrrrr}
\hline Case & $\begin{array}{r}\text { SST } \\
(\mathrm{K})\end{array}$ & $\begin{array}{r}\text { PW } \\
(\mathrm{mm})\end{array}$ & $\begin{array}{r}\text { PREC } \\
\left(\mathrm{mm} \mathrm{day}^{-1}\right)\end{array}$ & $\begin{array}{r}\text { SHF } \\
\left(\mathrm{W} \mathrm{m}^{-2}\right)\end{array}$ & $\begin{array}{r}\text { LHF } \\
\left(\mathrm{W} \mathrm{m}^{-2}\right)\end{array}$ \\
\hline IA50 & 300.52 & 40.82 & 3.17 & 10.25 & 92.30 \\
IA100 & 300.09 & 39.20 & 3.12 & 10.33 & 90.82 \\
IA200 & 299.60 & 37.50 & 3.07 & 10.45 & 89.27 \\
IA500 & 298.95 & 35.43 & 3.00 & 10.56 & 87.17 \\
IA1000 & 298.55 & 34.27 & 2.95 & 10.61 & 85.81 \\
IA2CO2 & 302.10 & 47.05 & 3.37 & 9.77 & 97.94 \\
FA50 & 300.00 & 38.92 & 3.10 & 10.32 & 89.96 \\
FA100 & 300.00 & 38.91 & 3.11 & 10.33 & 90.36 \\
FA200 & 300.00 & 38.91 & 3.13 & 10.40 & 90.91 \\
FA500 & 300.00 & 38.90 & 3.16 & 10.52 & 91.72 \\
FA1000 & 300.00 & 38.98 & 3.17 & 10.57 & 92.08
\end{tabular}

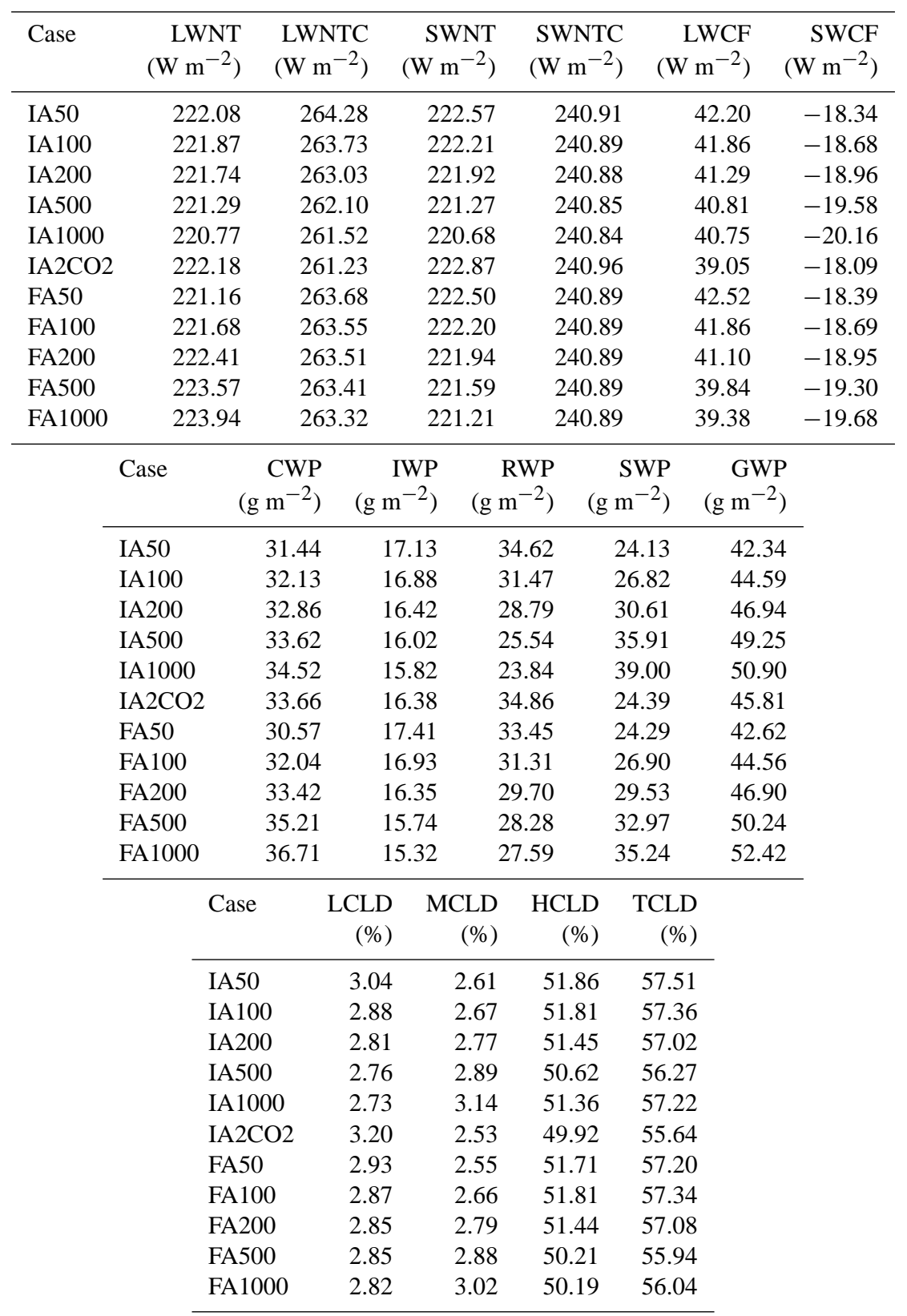


Table 3. Abbreviations.

\begin{tabular}{ll}
\hline Parameter & Explanation \\
\hline CWP & Cloud water path \\
HCLD & high-level cloud fraction as estimated by the ISCCP Cloud Simulator \\
IWP & Ice water path \\
GWP & Graupel water path \\
LCLD & low-level cloud fraction as estimated by the ISCCP Cloud Simulator \\
LHF & Latent heat flux \\
LWCF & longwave cloud radiative forcing \\
LWNT & net longwave radiation flux at the top of the atmosphere \\
LWNTC & net longwave radiation flux at the top of the atmosphere at clear sky \\
MCLD & mid-level cloud fraction as estimated by the ISCCP Cloud Simulator \\
PREC & surface precipitation \\
PW & precipitable water \\
RWP & rainwater water path \\
SHF & sensible heat flux \\
SST & sea surface temperature \\
SWCF & shortwave cloud radiative forcing \\
SWNT & net shortwave radiation flux at the top of the atmosphere \\
SWNTC & net shortwave radiation flux at the top of the atmosphere at clear sky \\
SWP & snow water path \\
TCLD & total cloud fraction as estimated by the ISCCP Cloud Simulator \\
\hline
\end{tabular}

susceptibility $S_{A}$ as the rate of change of some quantity $A$ with respect to change of decimal logarithm of $\mathrm{CCN}$ count:

$S_{A}=\partial A / \partial \log _{10}\left(C_{\mathrm{CCN}}\right)$

For the SST, the relative susceptibility due to indirect aerosol effects is estimated to be $-1.5 \mathrm{~K}$. It is worth noting that in our double- $\mathrm{CO}_{2}$ experiment (see Fig. 1 and Table 2), the SST increases by about $2 \mathrm{~K}$ in 700 days. Using the regression to the exponential-decay function, we estimate that the equilibrium climate sensitivity in our RCE runs is in the range $2.1-2.3 \mathrm{~K}$ per doubling of $\mathrm{CO}_{2}$, which is quite smaller than $2.9 \mathrm{~K}$ increases per doubling of $\mathrm{CO}_{2}$ obtained in highresolution cloud-resolving RCE simulations performed by Romps (2011). Interestingly, our estimate of the equilibrium climate sensitivity is consistent with $2.0 \mathrm{~K} \mathrm{SST}$ increase per doubling of $\mathrm{CO}_{2}$ found in climate-change simulations using idealised RCE-version of the ECHAM6 GCM (Popke at al., 2013). If we assume that the $\mathrm{CCN}$ concentration has followed the anthropogenic increase of aerosol from the preindustrial levels by $30 \%$ (Sekiguchi et al., 2003), then the corresponding decrease of SST is $-0.17 \mathrm{~K}$, which represents about $8 \%$ of our estimate for the SST warming due to doubling of $\mathrm{CO}_{2}$. Assuming a double- $\mathrm{CO}_{2}$ forcing of $3.7 \mathrm{~W} \mathrm{~m}^{-2}$ (e.g., IPCC, 2007), $8 \%$ implies an anthropogenic aerosol forcing of $-0.3 \mathrm{~W} \mathrm{~m}^{-2}$ due to the indirect effects. As discussed in Sect. 3.3, we believe that most of the indirect effect of aerosol in our model is due to the first (Twomey) effect.
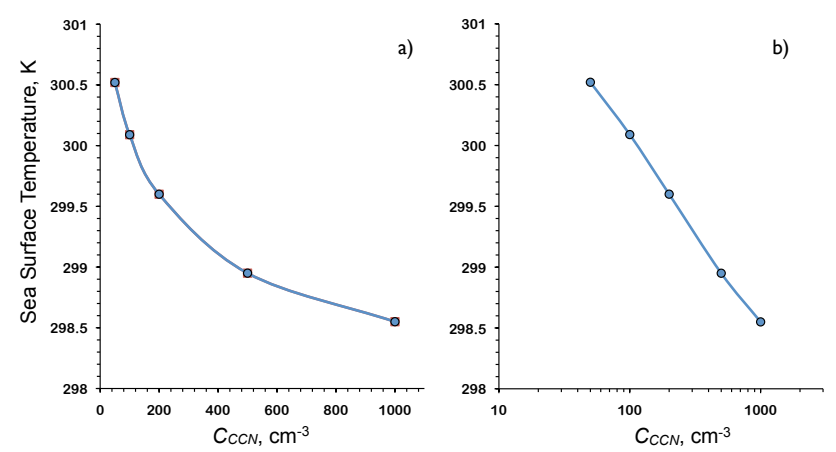

Fig. 2. Dependence of near-equilibrium SST on the CCN number concentration at $1 \%$ supersaturation plotted as (a) linear and (b) logarithmic scales.

\subsection{Radiative fluxes}

The top-of-atmosphere (TOA) shortwave and longwave radiation fluxes are shown by Fig. 3 and listed by Table 2. The effect of clouds on the radiation fluxes is usually described in terms of the cloud radiative forcing, which is the difference between TOA clear-sky and cloudy-sky fluxes. The response of the shortwave cloud forcing (SWCF), which is typically negative, to the increase of CCN count is similar between iSST and fSST cases, and consistent with the general consensus on the first AIE (Fig. 3a), that is the increase of CCN count makes SWCF more negative as clouds become brighter because of higher droplet concentrations and, hence, smaller droplets. The relative susceptibility of SWCF is estimated to 

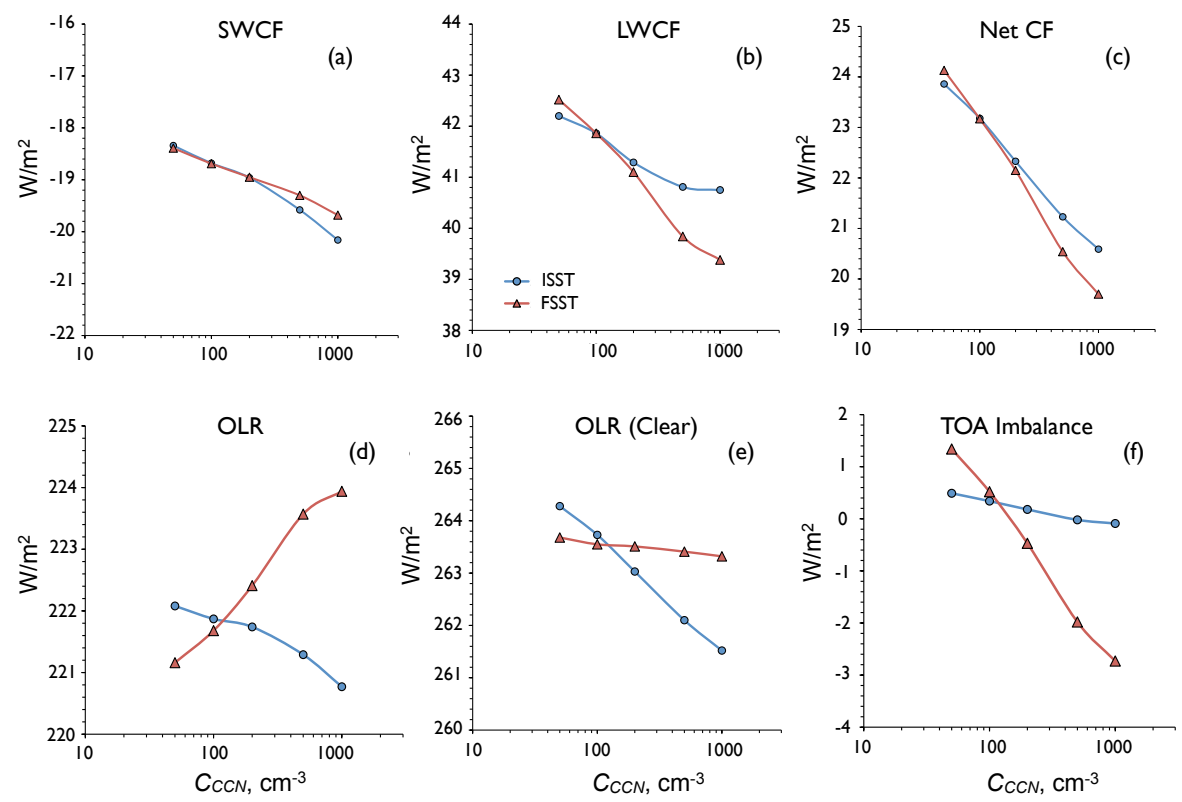

Fig. 3. Dependence of (a) SWCF, (b) LWCF, (c) SWCF + LWCF, (d) all-sky OLR, (e) clear-sky OLR, and (f) TOA radiation imbalance on CCN number concentration at $1 \%$ supersaturation in simulations with fixed (red) and interactive (blue) SST.

range from $-0.95 \mathrm{~W} \mathrm{~m}^{-2}$ in $\mathrm{fSST}$ cases to $-1.36 \mathrm{~W} \mathrm{~m}^{-2}$ in iSST cases. Virtually all of the SWCF change is from the change in absorbed shortwave radiation due to clouds, because the clear-sky solar absorbed radiation is not sensitive to changes in CCN (see Table 2).

In contrast to TOA shortwave fluxes, the net longwave radiative flux (LWNT; Table 2) or outgoing longwave radiation (OLR; Fig. 3d) shows a qualitatively different response between iSST and fSST cases. The changes in SST and the cloud water seem to be the key factors that may explain these qualitative differences. In iSST cases, the OLR decreases as SST cools in response to increasing CCN count, mainly due to decrease of the clear-sky OLR (Fig. 3e). On the other hand, in the fSST case, the clear-sky OLR changes are expectedly small, so that the effect of decreasing cloud fraction of anvils and corresponding ice water path (see Table 2) dominates the increase of OLR as more longwave radiation from the surface is able to reach the TOA. Despite these qualitative differences in OLR sensitivity, the sensitivity of the longwave cloud radiative forcing (LWCF; Fig. 3b), which is typically positive, to the increase of the CCN concentration is qualitatively similar between iSST and fSST cases. They both indicate the reduction of the greenhouse effect associated with clouds. Quantitatively though, the relative susceptibility of the LWCF in the fSST cases is about twice as high as in the iSST cases, -2.58 vs. $-1.25 \mathrm{~W} \mathrm{~m}^{-2}$.

The relative susceptibility of the total cloud radiative forcing (SWCF + LWCF; Fig. 3c) is rather similar in fSST and iSST cases, -3.53 vs. $-2.61 \mathrm{~W} \mathrm{~m}^{-2}$, respectively. The latter estimate is quantitatively consistent with the results of Menon et al. (2002), which concluded that AIE is responsible for a $1.2-3.0 \mathrm{~W} \mathrm{~m}^{-2}$ reduction of radiation over ocean, and the results of Ghan et al. (2001), which estimated the negative radiative forcing due to AIEs of about $1.5-3.0 \mathrm{~W} \mathrm{~m}^{-2}$.

In RCE, the net TOA radiative flux and the total surface flux (sum of latent, sensible and net radiation fluxes) should be equal; thus, the TOA imbalance (Fig. 3f) implies the tendency of the SST to change. As expected, in the iSST runs, the imbalance is generally small, less than $0.5 \mathrm{~W} \mathrm{~m}^{-2}$. It would take much longer runs to make the imbalance smaller. However, in the fSST runs, there is a clear strong tendency for the negative imbalance to increase with increasing CCN concentration. Such a relatively large imbalance would lead to rapid cooling of the SST if it was allowed to adjust.

\subsection{Hydrological cycle and cloud statistics}

As expected, the column integrated water vapour, or precipitable water, is virtually insensitive to $\mathrm{CCN}$ changes in fSST runs; however, it is very sensitive to $\mathrm{CCN}$ changes in iSST case, as illustrated by Fig. 4a. The relative susceptibility of the precipitable water in the latter case is $-5.2 \mathrm{~mm}$ or $13 \%$ relative to the control case, which is rather similar to the sensitivity given by the Clasius-Clapeyron relation in response to the reduction of SST. The precipitation in iSST cases decreases following the reduced radiative cooling of the atmosphere, with the estimated relative susceptibility of $-0.17 \mathrm{~mm} \mathrm{day}^{-1}$ or about $5 \%$ relative to the control case. The much slower rate of the precipitation change relative to the precipitable water change in response to the SST variation is explained by the notion that the equilibrium precipitation is mostly determined by the net radiative cooling, which 

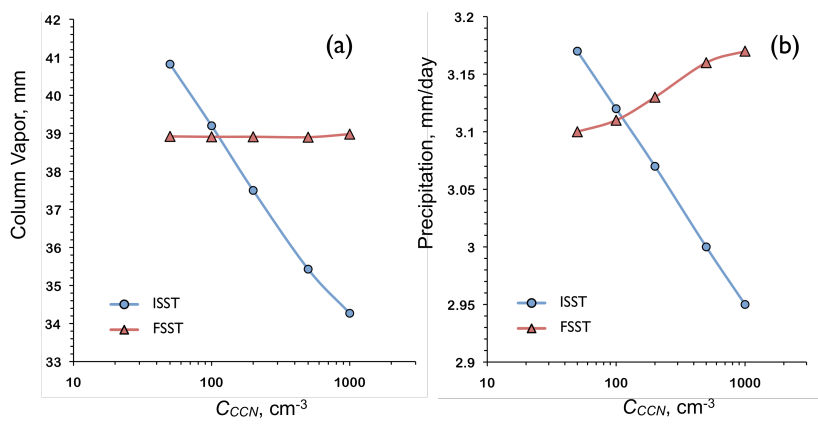

Fig. 4. Dependence of (a) column-integrated water vapour (precipitable water), and (b) surface precipitation on $\mathrm{CCN}$ number concentration at $1 \%$ supersaturation in simulations with fixed (red) and interactive (blue) SST.

does not change as fast as the water vapour mixing ratio (see, for example, Held and Soden, 2006). Despite constant precipitable water in the fSST cases, the precipitation rate tends to increase with increasing $\mathrm{CCN}$ count, with estimated relative susceptibility of $0.06 \mathrm{~mm} \mathrm{day}^{-1}$ or about $2 \%$ relative to the control case. Such a relatively minor change in precipitation rate is consistent with other studies (e.g., Rotstayn and Penner, 2001; van den Heever et al., 2011; Grabowski and Morrison, 2011; Morrison and Grabowski, 2011). The increase is the response to the modest increase of radiative cooling as indicated by the increase of OLR (see Fig. 3d). It has recently been argued (e.g., Rosenfeld et al., 2008) that in mixed clouds, the suppression of warm precipitation as the result of increasing $\mathrm{CCN}$ count would cause an additional freezing of liquid water, which would, in turn, lead to increase of cold-phase precipitation, so-called "rain invigoration" effect. Although the physics of the proposed invigoration effect is plausible on short time scales, in our RCE simulations, the radiative constrains on hydrological cycle over longer time scales clearly keep the relative increase of precipitation over constant SST relatively small.

The changes in cloud fraction (Table 2) have been estimated using the ISCCP (International Satellite Cloud Climatology Project; Rossow and Schiffer, 1999) Simulator (Klein and Jacob, 1999). The Simulator samples the clouds to mimic cloud fraction retrieval from a satellite, which is most relevant to the estimates of the TOA radiative fluxes. For example, low-level clouds underneath a thick anvil cloud would not be seen by a satellite in both shortwave and longwave parts of the spectrum and, thus, would not contribute to the estimate of the low-level cloud fraction. Sampled clouds are subdivided into three categories according to cloud-top pressure: low, middle and high. In our RCE simulations, most of the $57 \%$ of the total cloud fraction as seen by the ISCCP Simulator is due to high-level clouds. From Table 2, it follows that as CCN count increases, the fractions of highlevel (HCLD) and low-level (LCLD) clouds tend to decrease, while the fraction of mid-level (MCLD) clouds tends to in- crease. However, the absolute changes in cloud fraction are rather small, which is consistent with previous CRM studies of the indirect aerosol effects (e.g., Grabowski, 2006; van den Heever et al., 2011).

In contrast to cloud fraction, the changes in column integrals, or paths, of all five prognostic water-content variables (cloud liquid water, cloud ice, rainwater, snow and graupel) in response to increasing $\mathrm{CCN}$ concentration are robust and qualitatively similar between the iSST and fSST cases, as shown by Fig. 5. Higher CCN counts and, hence, smaller cloud droplets result in suppression of warm rain production and, consequently, in increase of the liquid water path (Fig. 5a), which is consistent with the observational study by Lebsock et al. (2008) for the case of precipitating clouds. Corresponding relative susceptibility in the fSST case is about twice as high as in the iSST case (4.6 vs. $2.3 \mathrm{~g} \mathrm{~m}^{-3}$, or $14 \%$ vs. $7 \%$ with respect to the control). Higher cloud liquid water content means more water is transported above the freezing level, and as a result more water is available for the cold-phase precipitation processes. This explains the monotonic increase of snow (Fig. 5d) and graupel (Fig. 5e) water paths and the corresponding decrease of the column cloud ice (Fig. 5b) as the result of accretion by the frozen precipitation.

The optical depth of clouds is generally proportional to the cloud water path and inversely proportional to the effective radius (e.g., Stephens, 1978). The model diagnostics allows one to estimate the effective radius using the Moderate Resolution Imaging Spectroradiometer (MODIS) simulator package (Pincus et al., 2012). The simulated liquid effective radius as a function of the CCN count is shown in Fig. 5c. As expected, the liquid effective radius is the largest (about $13 \mu \mathrm{m}$ ) for the pristine and the smallest (about $7 \mu \mathrm{m}$ ) for the polluted conditions for both of the iSST and fSST cases. The change in the cloud optical path as the result of change in the effective radius can be viewed as the first indirect effect, while the change in the cloud water path as the second indirect effect. For cloud ice, the effective radius is large and is not sensitive to the change in CCN. Also, the cloud ice path difference between the pristine and polluted conditions is relatively small, about $10 \%$. Thus, most of the effect on the shortwave optical path is due to the liquid clouds. The relative change in the liquid effective radius between the pristine and polluted conditions is almost a $100 \%$, while the corresponding change of the cloud water path is only about $15-20 \%$. Thus, in our simulations, the effect of $\mathrm{CCN}$ on the cloud optical path is dominated by the first (Twomey) indirect effect, which is consistent with Grabowski (2006).

The vertical profiles of the relative change of horizontally averaged cloud and precipitating water-content variables with respect to the control runs are shown in Fig. 6 . In fSST cases, the changes in CCN count do not have a notable effect on clouds below $2 \mathrm{~km}$, simply because of relatively small liquid cloud content and, consequently, insignificant warm rain production. In the iSST cases, though, there is a considerable decrease of cloud water below $2 \mathrm{~km}$, which 

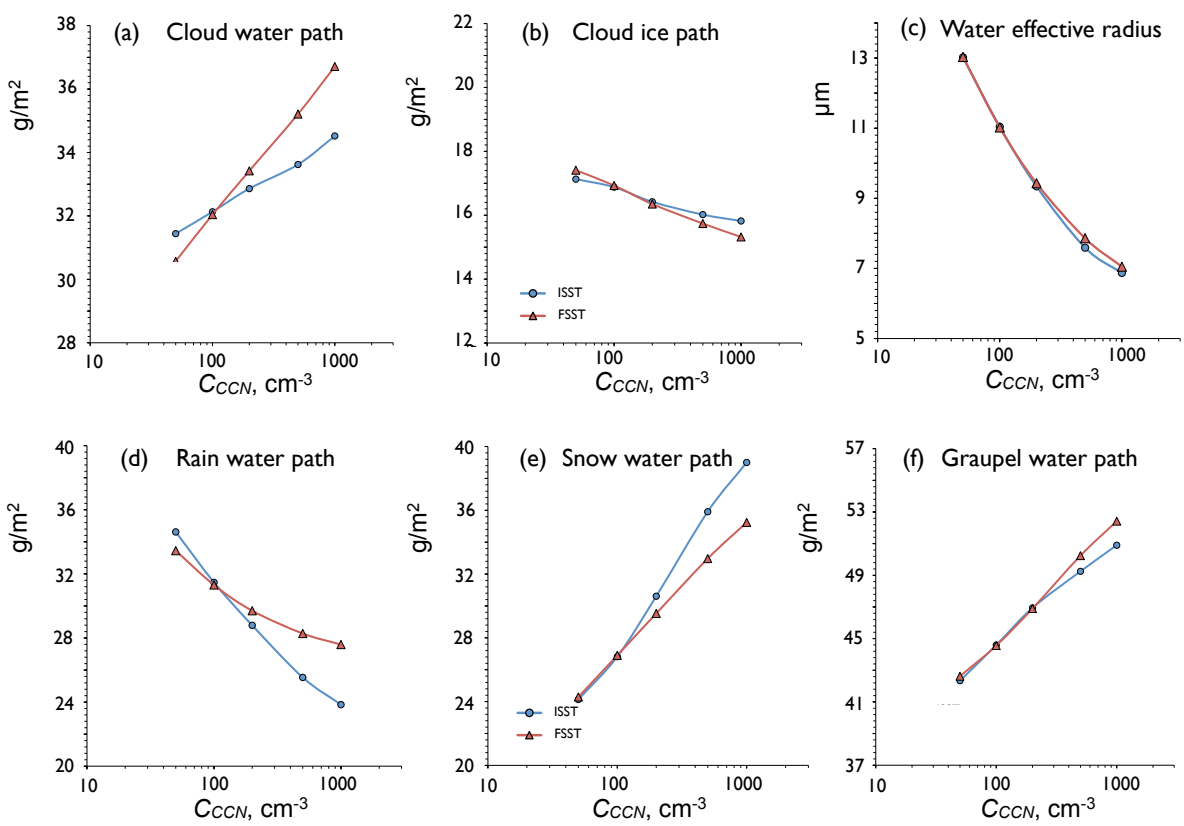

Fig. 5. Dependence of column-integrated (a) liquid cloud water, (b) cloud ice, (d) rain water, (e) snow water, (f) graupel water and of (c) liquid effective radius on CCN number concentration at $1 \%$ supersaturation in simulations with fixed (red) and interactive (blue) SSTs.

could be explained by mixing with the dryer environment, which tends to reduce the liquid water content at cooler SSTs. In the main warm-rain production region above $2 \mathrm{~km}$, the microphysical effects of $\mathrm{CCN}$ increase are similar in the fSST and iSST cases, that is, the increase tends to suppress rain production and, consequently, increase cloud liquid water. The reduction of the rainwater content for the same $\mathrm{CCN}$ count is larger in the iSST cases because of the overall reduction of available water vapour in response to cooler SSTs. However, in the mixed-phase cloud regions, below $9 \mathrm{~km}$, the amount of the frozen precipitation for the same CCN count is higher in the iSST cases despite the cooler SSTs. This is probably because the cooler troposphere temperature in iSST cases causes a local increase of cloud ice as the result of heterogeneous freezing and further increase of cloud ice due to the Bergeron-Findeisen process, which also contributes to the increased production of the frozen precipitation. The effect of lower availability of water vapour in the iSST cases becomes apparent above $9 \mathrm{~km}$ in the anvil region, where the reduced amount of cloud ice results in corresponding reduction of snow and graupel.

Despite qualitative and quantitative similarity in response of the hydrometeors to CCN changes in the iSST and fSST cases, the responses of precipitation flux are rather different, as shown in Fig. 7. Note that precipitation flux for a given hydrometeor depends nonlinearly on water content and number concentration. The conversion rates for the moments in two-moment bulk microphysics scheme used in this study are also complicated and nonlinear functions of the moments themselves as well as of other variables such as tempera- ture and humidity. Therefore, it is rather difficult to untangle all the details of precipitation flux changes in response to changes in $\mathrm{CCN}$ count. However, qualitatively, the difference between the iSST and fSST cases is mostly due to the thermodynamic response of convection to changes in water vapour amount as a result of SST changes and also changes in the efficiency of cloud liquid water conversion to rain. In the fSST cases, the reduction of the conversion efficiency increases the amount of water available for the cold-phase precipitation processes, which results in an overall increase of precipitation flux (Fig. 7b). On the other hand, in the iSST cases, a decrease of water vapour in response to SST cooling becomes as powerful a factor in determining the precipitation rate as the changes in cloud microphysics. Overall, there is a robust reduction of precipitation flux at all levels in iSST cases relative to fSST cases for the same CCN count (Fig. 7a).

\section{Summary}

This study examines the aerosol indirect effects (AIEs) in an idealised tropical atmosphere using a three-dimensional cloud-resolving model with a two-moment bulk microphysics and interactive radiation. All runs use a threedimensional doubly periodic $128 \times 128 \times 28 \mathrm{~km}$ domain with the horizontal grid spacing of $1 \mathrm{~km}$. On long temporal and spatial scales, the tropical convection can be viewed as the equilibrium response to the large-scale destabilisation by radiation, surface enthalpy fluxes and large-scale circulation. 

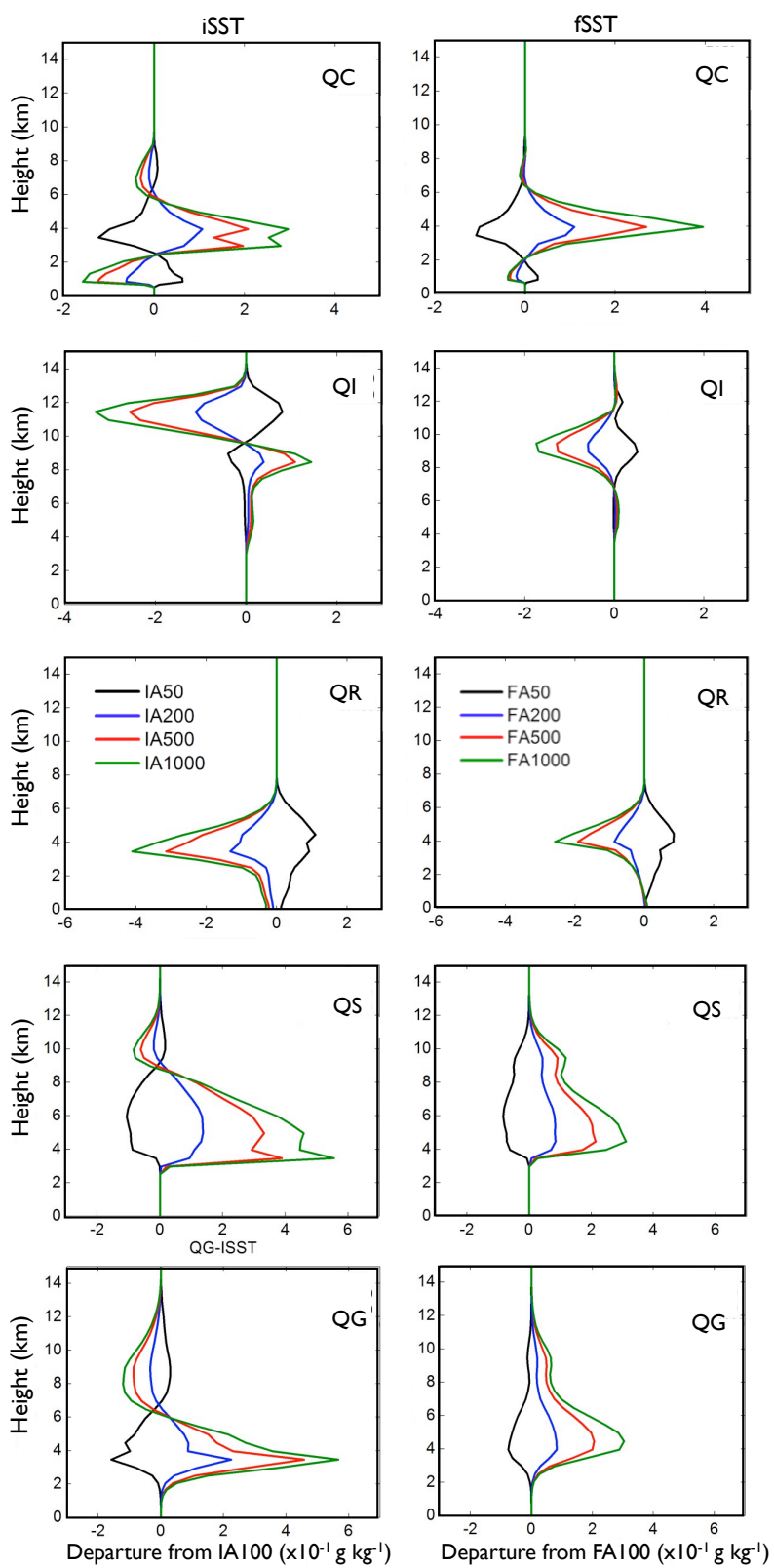

Fig. 6. Vertical profiles of departure from the control (IA100 and FA100) of the mixing ratio in $10^{-3} \mathrm{~g} \mathrm{~kg}^{-1}$ of cloud liquid water $(\mathrm{QC})$, rain water $(\mathrm{QR})$, cloud ice (QI), snow (QS), and graupel (QG) for interactive (left panels) and fixed (right panels) SSTs.

We use a radiative-convective equilibrium as idealisation of the tropical atmosphere, in which the radiation and surface fluxes are interactively computed, but the effects of largescale circulation are ignored. The novel feature of this study is the use of interactive SST as predicted by a simple slab ocean model. This approach is much more computationally expensive than a commonly used fixed-SST approach, because it takes relatively long integration time (hundreds of days) to approach equilibrium.
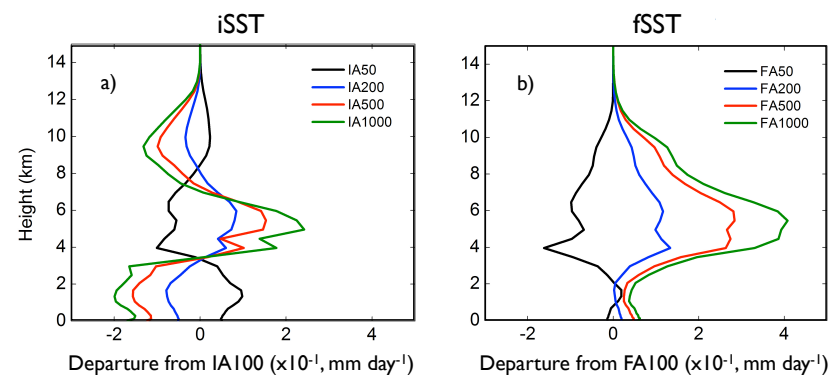

Fig. 7. Vertical profiles of the departures from the control (IA100 and FA100) of precipitation flux, $10-1 \mathrm{~mm} \mathrm{day}^{-1} 1$ for (a) interactive and (b) fixed SST.

The aerosol effects on clouds are modelled by prescribing the activation spectrum of cloud condensation nuclei $(\mathrm{CCN})$. The $\mathrm{CCN}$ count is defined as $\mathrm{CCN}$ concentration at $1 \%$ supersaturation. For each prescribed or prognostic SST case, five runs with increasing $\mathrm{CCN}$ count have been performed. The CCN count has been changed in a rather wide range, from values that are typical for pristine maritime conditions $\left(50 \mathrm{~cm}^{-3}\right)$ to values that are typical for maritime polluted or even continental-like conditions $\left(1000 \mathrm{~cm}^{-3}\right)$. Note that no direct effect of $\mathrm{CCN}$ on radiation has been included.

As expected, the SST decreases in response to increasing $\mathrm{CCN}$ count. It is found that the SST sensitivity to the absolute change in $\mathrm{CCN}$ is substantially higher for clean than for polluted conditions. However, the SST response to the relative change in $\mathrm{CCN}$ is independent of $\mathrm{CCN}$ conditions. For example, doubling the CCN count in clean maritime conditions causes the same drop in SST as doubling the CCN count in polluted conditions. A similar behaviour is found for other bulk quantities, such as top-of-atmosphere radiative fluxes, precipitation rate, precipitable water, among others. As a quantitative measure of sensitivity of some given quantity to relative change in $\mathrm{CCN}$ count, we use the relative susceptibility defined as the rate of change of that quantity in response to the change of decimal logarithm of CCN concentration. For example, the relative susceptibility of the SST is found to be $-1.5 \mathrm{~K}$, which means that it would take one order of magnitude increase of CCN count to cool the SST by that amount. Note that this cooling may effectively mitigate the 2.1-2.3 $\mathrm{K}$ warming found in the run with clean maritime conditions, but doubled $\mathrm{CO}_{2}$ concentration. Assuming the aerosol concentration has increased from preindustrial time by $30 \%$, the radiative forcing due to indirect aerosol effects is estimated to be $-0.3 \mathrm{~W} \mathrm{~m}^{-2}$.

The shortwave cloud forcing (SWCF) due to CCN increase is found to become more negative in both the fSST and iSST runs, which is consistent with the first indirect aerosol effect or so-called cloud-albedo effect. The relative susceptibility of the SWCF is found to be $-0.95 \mathrm{~W} \mathrm{~m}^{-2}$ and $-1.36 \mathrm{~W} \mathrm{~m}^{-2}$, respectively, with virtually no changes in clear-sky shortwave radiation. The magnitude of cooling in 
the shortwave part of the spectrum is matched or even exceeded by the reduction in the longwave cloud radiative forcing (LWCF); however, the mechanism for the effect is different between the fSST and iSST cases. In the fSST cases, the reduction is dominated by the decrease of the greenhouse effect of clouds, while in the iSST cases, it is mostly due to the decrease of the clear-sky greenhouse effect caused by reduction of precipitable water in response to cooler SSTs. The magnitude of relative susceptibility of LWCF in the fSST case is found to be twice as large as in the iSST case, $-2.58 \mathrm{~W} \mathrm{~m}^{-2}$ vs. $-1.25 \mathrm{~W} \mathrm{~m}^{-2}$. Relative susceptibility of the net cloud radiative forcing (SWCF+LWCF) is found to be $-3.53 \mathrm{~W} \mathrm{~m}^{-2}$ in the fSST case and $-2.61 \mathrm{~W} \mathrm{~m}^{-2}$ in the iSST case.

There are pronounced differences between the fSST and iSST cases in the simulated hydrological cycles. In the fSST case, the precipitable water is virtually insensitive to changes in CCN count as it mostly determined by the fixed SST, while in the iSST case, the precipitable water closely follows the SST trend, as dictated by the Clasius-Clapeyron relation. The relative susceptibility of precipitable water is found to be $-5.2 \mathrm{~mm}$ or $13 \%$ decrease per order of magnitude increase of CCN count. It is interesting that the sensitivity of precipitation rate is found to be different in sign between the fSST and iSST cases. In the fSST case, the precipitation rate tends to increase slightly in response to increasing $\mathrm{CCN}$ count with susceptibility of $0.06 \mathrm{~mm} \mathrm{day}^{-1}$ or about $2 \%$. However, in the iSST case, the precipitation decreases following the reduced radiative cooling of the atmosphere with the relative susceptibility of $-0.17 \mathrm{~mm} \mathrm{day}^{-1}$ or $-5 \%$.

The response of the column integrals of cloud condensate and hydrometeors is found to be qualitatively similar between the fSST and iSST cases. The liquid water path (LWP) tends to increase with increasing CCN count as a result of suppression of warm rain production. The relative susceptibility of LWP is $4.6 \mathrm{~g} \mathrm{~m}^{-2}(14 \%)$ in fSST case vs. $2.3 \mathrm{~g} \mathrm{~m}^{-2}$ (7\%) in iSST case. As liquid water content increases, more water becomes available for cold-phase precipitation processes above the freezing level. As a result, the snow and graupel water paths increase at the expense of the cloud ice water path. We also estimated that the contribution to the optical path is dominated by the change in the liquid effective radius (almost a factor of 2 ) over the change in the cloud water path (a factor of 1.2); therefore, the IAE in our study is dominated by the first (Twomey) effect.

The results of this study demonstrate the importance of including the SST feedback when estimating the AIEs. The RCE over the fixed SST develops a significant negative surface energy imbalance when conditions change from clean to polluted. Such an imbalance, given sufficient time, would force the SSTs to cool, which would affect the thermodynamic state and radiation field and, consequently, the convection itself. Arguably, such a slow response of simulated tropics to prolonged aerosol forcing may be more relevant to the climate-change problem and so-called "geo- engineering" mitigation strategy. The AIEs estimated in a fixed-SST framework may represent a fast response of tropical convection to changes in aerosol forcing on relatively short time scales of a few days or, perhaps, as long as a few weeks, during which the SST stays relatively unchanged due to the ocean's large thermal inertia. The fast and slow feedbacks of the tropical convection to aerosol forcing can be qualitatively different as shown for the case of the precipitation response.

In conclusion, it should be noted that the results reported here have been obtained using an idealised framework of radiative-convective equilibrium with no feedback to largescale circulation, which can also affect the response of tropical convection to AIEs. We also do not know how sensitive our results are to the choice of the microphysics scheme with its simplified treatment of $\mathrm{CCN}$ as constant background with no sources and sinks. Due to relatively high computational cost of the RCE simulations over interactive SST, no test of sensitivity of our results to the grid spacing and domain size has been performed. The simulations of small shallow clouds can particularly be sensitive to the grid spacing. The relatively small domain size used in this study could also prevent possible changes in convective organisation in response to modification of cloud microphysics and radiation caused by changes in aerosols. These are just a few caveats among many others that need to be addressed in the future numerical studies of indirect aerosol effects.

Acknowledgements. This research was supported by the National Oceanic and Atmospheric Administration (NOAA) grant NA08OAR4310544 to Stony Brook University. M. K. was also supported by the NSF Science and Technology Center for Multiscale Modeling of Atmospheric Processes (CMMAP), managed by Colorado State University under cooperative agreement ATM0425247. Computing resources were provided by the New York Center for Computational Science, which is a joint venture between Stony Brook University and Brookhaven National Laboratory.

Edited by: B. Stevens

\section{References}

Abdul-Razzak, H. and Ghan, S. J.: A parameterization of aerosol activation: 3. Sectional representation, J. Geophys. Res., 107, 4026, doi:10.1029/2001JD000483, 2002.

Albrecht, B.: Aerosols, cloud microphysics, and fractional cloudiness, Science, 245, 1227-1230, 1989.

Ghan, S. J., Easter, R. C., Chapman, E. G., Abdul-Razzak, H., Zhang, Y., Leung, L. R., Laulainen, N. S., Saylor, R. D., and Zaveri, R. A.: A physically based estimate of radiative forcing by anthropogenic sulfate aerosol, J. Geophys. Res., 106, 52795293, doi:10.1029/2000JD900503, 2001.

Grabowski, W. W.: Indirect impact of atmospheric aerosols in idealized simulations of convective-radiative quasi equilibrium, J. Climate, 19, 4664-4682, 2006. 
Grabowski, W. W. and Morrison, H.: Indirect Impact of Atmospheric Aerosols in Idealized Simulations of ConvectiveRadiative Quasi Equilibrium. Part II: Double-Moment Microphysics, J. Climate, 24, 1897-1912, 2011.

Held, I. M. and Soden, B. J.: Robust responses of the hydrological cycle to global warming, J. Clim., 19, 5686-5699, 2006.

Hoose, C., Kristjánsson, J. E., Chen, J.-P., and Hazra, A.: A classical-theory-based parameterization of heterogeneous ice nucleation by mineral dust, soot, and biological particles in a global climate model, J. Atmos. Sci., 67, 2483-2503, doi:10.1175/2010JAS3425.1, 2010.

Iacono, M. J., Delamere, J., Mlawer, E., Shephard, M., Clough, S., and Collins, W.: Radiative forcing by long-lived greenhouse gases: Calculations with the AER radiative transfer models, J. Geophys. Res., 113, D13103, doi:10.1029/2008JD009944, 2008.

IPCC, 2007: Climate Change: The Physical Science Basis. Contribution of Working Group I to the Fourth Assessment Report of the Intergovernmental Panel on Climate Change, edited by: Solomon, S., Qin, D., Manning, M., Chen, Z., Marquis, M., Averyt, K. B., Tignor, M., and Miller, H. L., Cambridge University Press, Cambridge, United Kingdom and New York, NY, USA, 2007.

Khairoutdinov, M. F. and Randall, D. A.: Cloud-resolving modelling of the ARM summer 1997 IOP: model formulation, results, uncertainties and sensitivities, J. Atmos. Sci., 60, 607-625, 2003.

Klein, S. and Jacob, C.: Validation and sensitivities of frontal clouds simulated by the ECMWF model, Mon. Weather Rev., 127, 2514-2531, 1999.

Lebsock, M. D., Stephens, G. L., and Kummerow, C.: Multisensor satellite observations of aerosol effects on warm clouds, J. Geophys. Res., 113, D15205, doi:10.1029/2008JD009876, 2008.

Liu, X. and Penner, J. E.: Ice nucleation parameterization for global models, Meteorol. Z., 14, 499-514, doi:10.1127/09412948/2005/0059, 2005.

Lohmann, U. and Feichter, J.: Global indirect aerosol effects: a review, Atmos. Chem. Phys., 5, 715-737, doi:10.5194/acp-5-7152005, 2005.

Lu, M.-L. and Seinfeld, J. H.: Study of the aerosol indirect effect by large-eddy simulation of marine stratocumulus, J. Atmos. Sci., 62, 3909-3932, doi:10.1175/JAS3584.1, 2005.

Menon, S., Del Genio, A. D., Koch, D., and Tselioudis, G.: GCM Simulations of the Aerosol Indirect Effect: Sensitivity to Cloud Parameterization and Aerosol Burden, J. Atmos. Sci., 59, 692713, 2002.

Morrison, H., Curry, J. A., and Khvorostyanov, V. I.: A new doublemoment microphysics parameterization for application in cloud and climate models. Part I: Description, J. Atmos. Sci., 62, 1665$1677,2005$.

Morrison, H. and Grabowski, W. W.: Cloud-system resolving model simulations of aerosol indirect effects on tropical deep convection and its thermodynamic environment, Atmos. Chem. Phys., 11, 10503-10523, doi:10.5194/acp-11-10503-2011, 2011.

Nenes, A. and Seinfeld, J. H.: Parameterization of cloud droplet formation in global climate models, J. Geophys. Res., 108, 4415, doi:10.1029/2002JD002911, 2003.

Iacono, M. J., Delamere, J., Mlawer, E., Shephard, M., Clough, S., and Collins, W.: Radiative forcing by long-lived greenhouse gases: Calculations with the AER radiative transfer models, J.
Geophys. Res., 113, D13103, doi:10.1029/2008JD009944, 2008.

Pincus, R. and Baker, M. B.: Effect of precipitation on the albedo susceptibility of clouds in the marine boundary layer, Nature, 372, 250-252, doi:10.1038/372250a0, 1994.

Pincus, R., Platnick, S., Ackerman, S. A., Hemler, R. S., and Hofmann, R. J. P.: Reconciling Simulated and Observed Views of Clouds: MODIS, ISCCP, and the Limits of Instrument Simulators, J. Climate, 25, 4699-4720, 2012.

Platnick, S. and Oreopoulos, L.: Radiative susceptibility of cloudy atmospheres to droplet number perturbations: 1. Theoretical analysis and examples from MODIS, J. Geophys. Res., 113, D14S20, doi:10.1029/2007JD009654, 2008.

Popke, D., Stevens, B., and Voigt, A.: Climate and climate change in a radiative-convective equilibrium version of ECHAM6, J. Adv. Model. Earth Syst., doi:10.1029/2012MS000191, in press, 2013.

Pruppacher H. R. and Klett, J. D.: Microphysics of clouds and precipitation, Kluwer Academic Publishers, USA, 1997.

Rennó, N. O., Emanuel, K. A., and Stone, P. H.: Radiativeconvective model with an explicit hydrological cycle, Part I: Formulation and sensitivity to model parameters, J. Geophys. Res., 99, 14429-14441, 1994.

Romps, D. M.: Response of tropical precipitation to global warming, J. Atmos. Sci., 68, 123-138, 2011.

Rosenfeld, D., Lohmann, U., Raga, G. B., O’Dowd, C. D., Kulmala, M., Fuzzi, S., Reissell, A., and Andreae, M.: Flood or drought: How do aerosols affect precipitation?, Science, 321, 1309-1313, 2008.

Rossow, W. B. and Schiffer, R. A.: Advances in understanding clouds from ISCCP, B. Am. Meteorol. Soc., 80, 2261-2288, 1999.

Rotstayn, L. D. and Penner, J. E.: Indirect aerosol forcing, quasi forcing, and climate response, J. Climate, 14, 2960-2975, 2001.

Sekiguchi, M., Nakajima, T., Suzuki, K., Kawamoto, K., Higurashi, A., Rosenfeld, D., Sano, I., and Mukai, S.: A study of the direct and indirect effects of aerosols using global satellite data sets of aerosol and cloud parameters, J. Geophys. Res., 108, 4699, doi:10.1029/2002JD003359, 2003.

Stephens, G. L.: Radiation profiles in Extendent water clouds. II: Parameterization schemes, J. Atmos. Sci., 35, 2123-2132, 1978.

Stephens, G. L., van den Heever, S., and Pakula, L.: Radiativeconvective feedbacks in idealized states of radiative-convective equilibrium, J. Atmos. Sci., 65, 3899-3916, 2008.

Tao, W.-K., Li, X., Khain, A., Matsui, T., Lang, S., and Simpson, J.: Role of atmospheric aerosol concentration on deep convective precipitation: cloud-resolving model simulations, J. Geophys. Res., 112, D24S18, doi:10.1029/2007JD008728, 2007.

Tompkins, A. M. and Craig, G. C.: Radiative-convective equilibrium in a three-dimensional cloud ensemble model, Q. J. Roy. Meteor. Soc., 124, 2073-2097, 1998.

Twomey, S.: The nuclei of natural cloud formation. Part II: the supersaturation in natural clouds and the variation of cloud droplet concentrations, Pure Appl. Geophys., 43, 243-249, 1959.

Twomey, S:: Pollution and the planetary albedo, Atmos. Environ., 8, 1251-1256, 1974.

van den Heever, S. C., Stephens, G. L., and Wood, N. B.: Aerosol indirect effects on tropical convection characteristics under conditions of radiative-convective equilibrium, J. Atmos. Sci., 68, 699-718, doi:10.1175/2010JAS3603.1, 2011. 
Wang, M., Ghan, S., Easter, R., Ovchinnikov, M., Liu, X., Kassianov, E., Qian, Y., Gustafson Jr., W. I., Larson, V. E., Schanen, D. P., Khairoutdinov, M., and Morrison, H.: The multiscale aerosol-climate model PNNL-MMF: model description and evaluation, Geosci. Model Dev., 4, 137-168, doi:10.5194/gmd-4137-2011, 2011.
Xu, K.-M. and Randall, D. A.: A sensitivity study of radiativeconvective equilibrium in the tropics with a convection-resolving model, J. Atmos. Sci., 56, 3385-3399, 1999. 